\title{
Portfólio Reflexivo: \\ avaliar e avaliar-se
}

Reflexive Portfolio

to assess and self-assess

Portafolio Reflexivo:

evaluar y evaluarse

FRANCISCO PAULO RODRIGUES MESTRE*

Secretaria Municipal de Educação de Guaporé, Guaporé, RS, Brasil.

MARLI TERESINHA QUARTIERI ${ }^{* *}$

Universidade do Vale do Taquari, Lajeado, RS, Brasil.

JACQUELINE SILVA DA SILVA**

Universidade do Vale do Taquari, Lajeado, RS, Brasil.

RESUMO: O artigo tem como objetivo discutir questões do avaliar e da autoavaliação no ambiente escolar, lançando reflexões a respeito de formas e possibilidades de ruptura nos "novos velhos" conceitos de processos avaliativos. Apresenta relato de uma experiência sobre avaliação por meio da utilização de Portfólio Reflexivo com turmas de anos finais do ensino fundamental e as contribuições de sua utilização nos processos avaliativos. O portfólio mostrou-se uma experiência enriquecedora, repleta de possibilidades para aluno e professor identificarem suas potencialidades e fragilidades.

Palavras-chave: Avaliação. Autoavaliação. Portfólio Reflexivo.

* Pedagogo, tem experiência em educação musical. Mestrando em Ensino (UNIVATES). Atualmente é professor da Secretaria Municipal de Educação de Guaporé. E-mail: xykomestre@gmail.com.

** Doutora em Educação pela Unisinos. Professora da Univates, atuando nos cursos de graduação e do programa de pós-graduação em Ensino. Tem experiência na área de ciências exatas, com ênfase no ensino de matemática.E-mail: mtquartieri@univates.br.

* Doutora em Educação pela UFRGS. Professora do programa de pós-graduação em Ensino da Univates. Tem experiência na área de Educação, com ênfase em Educação Infantil. E-mail: jacqueh@univates.br. 


\begin{abstract}
The article aims to discuss issues of assessment and self -assessment in school environment, projecting thoughts on forms and possibilities of rupture in the "new old" concepts of evaluation processes. It presents an experiential report on evaluation by means of Reflective Portfolio (RP) in classes of final years of elementary education and the contributions of its use in evaluation processes. The portfolio has proved to be an enriching experience, full of possibilities for students and teachers to identify potentialities and weaknesses.
\end{abstract}

Keywords: Assessment. Self-assessment. Reflexive Portfolio.

RESUMEN: El artículo tiene como objetivo discutir cuestiones de la evaluación y de la autoevaluación en el ambiente escolar, lanzando reflexiones respecto a las formas y posibilidades de ruptura en los "nuevos viejos" conceptos de procesos evaluativos. Presenta relato de una experiencia sobre evaluación por medio de la utilización de Portafolio Reflexivo con clases de años finales de la enseñanza fundamental y las contribuciones de su utilización en los procesos de evaluación. El portafolio se mostró una experiencia enriquecedora, repleta de posibilidades para que el alumno y el profesor identifiquen sus potencialidades y fragilidades.

Palabras clave: Evaluación. Autoevaluación. Portfolio Reflexivo.

\title{
Introdução
}

\section{"Conhece-te a ti mesmo" \\ (SÓCRATES apud EGG, 2009, p. 6)}

máxima socrática descrita por seus discípulos, principalmente Platão, aponta
a preocupação da inter e intra relação humana e as discussões sobre verdade
e conhecimento. Segundo Foucault (2004), devemos incorporar essa relação humana à estratégia mais geral do cuidado de si pautado na verdade e na ética. Cuidado em si, conhecer a si como forma de desenvolver a consciência sobre o que mudar, almejando a melhoria das relações para comigo, com o(s) outro(s) e com a sociedade à qual pertenço em meu tempo. Então, na Grécia, há mais de 400 anos a.C, Sócrates sugeria a autoavaliação como necessária à adaptação do homem ao mundo quando adotou o aforismo "conhece-te a ti mesmo". A frase, que se encontra inscrita na entrada do templo 
de Delfos em honra a Apolo, o deus grego do sol, da beleza e da harmonia, teria sido tomada por Sócrates para desenvolver sua filosofia.

Até hoje, principalmente na área da filosofia, ouvimos muito sobre a máxima de Sócrates, instituindo-se várias denominações, desdobramentos e ramificações, sendo alguns deles a autoavaliação, a avaliação, a metacognição. Estas percorrem algumas áreas do conhecimento, tais como a psicologia e o ensino. Também observamos o implemento de estratégias, procedimentos, ferramentas e processos que possibilitam o encontro do desenvolvimento do conhecimento e autoconhecimento por meio da avaliação.

Quando falamos em autoconhecimento e avaliação, voltamos a atenção ao Portfólio reflexivo como estratégia significativa de avaliação e autoavaliação dentro dos processos de ensinar e aprender no ambiente escolar. Sua utilização exige um olhar atento aos movimentos do cotidiano escolar, tomada de consciência e decisões que, por vezes, tornam-se obstáculos à compreensão. Exige a desacomodação, a desconstrução de conhecimentos para ressignicá-los e reconstruí-los a partir de experiências já vivenciadas. Exige abandonar a zona de conforto, aventurando-nos por um mundo de possibilidades.

\section{Desacomodação necessária}

\section{"Dói a história, dói o esforço, dói a mudança. A dor já não é sofrimento, é uma cáustica virtude imposta pelo roteiro da vida" \\ (PECCI, 1986, p. 147)}

Conhecer e conhecer-se, avaliar e auto avaliar-se em uma busca incessante de superação da inércia, do lugar comum instaurado nos processos de ensinar e aprender, pode tornar-se doloroso. Doloroso por exigir trabalho, pesquisa, crítica e autocrítica, vontade e disponibilidade para exploração, criação e recriação, frustração. Depende de metodologias, instrumentos avaliativos, coleta e processamento de dados que possam indicar um caminho certo (ou não). Doloroso por exigir rupturas, mudanças, acompanhamento da evolução tecnológica, da dinâmica social. Doloroso por ser necessário abandonar o modelo cômodo tradicional onde o professor era o transmissor de conhecimento, através da cópia e repetição, substituindo este modelo pela mediação participativa, dialógica entre professor, aluno e conhecimento. Doloroso, por exigir o abandono da zona de conforto, embrenhando-nos por trilhas e escaladas desconhecidas ou evitadas ou, ainda, até então ignoradas.

Neste contexto, a análise dos instrumentos avaliativos pode servir como aliada ao aperfeiçoamento das práticas pedagógicas cotidianas, ampliando a visão do professor e 
do aluno. Ainda pode ser utilizada como ferramenta de auto avaliação profissional, de questionamentos aos argumentos e metodologias docentes, que, por vezes, serve para um aluno e pode não servir para outro, visto a heterogenia nas salas de aulas.

Não podemos sucumbir ao enfoque tradicionalista da avaliação, de argumento classificatório, punitivo, diagnóstico de sucesso ou de fracasso do aluno, decretando seu avanço ou retenção na mesma etapa de ensino. Será necessário sujeitar ao aluno repetir um ano na mesma disciplina, com o mesmo professor, os mesmos conteúdos e as mesmas metodologias que não surtiram efeito para ele? Ademais, deverá, neste período, repetir as demais disciplinas em que foram atingidos os objetivos?

Avaliar e avaliar-se não configura um consenso simples ou tranquilo. Trata-se de um processo complicado, tanto para os que se dedicam às teorias quanto para quem se envolve com a prática avaliativa (SOBRINHO, 2004). Principalmente porque implica proporcionar uma reflexão que venha a gerar mudanças, superações, crescimento. Implica a busca por aperfeiçoamento constante de possibilidades de aprendizagem e de desenvolvimento, pela desconstrução e reconstrução de conhecimentos, respeitando a diversidade dos atores no cotidiano escolar (ALBERTINO e SOUZA, 2004). Avaliar exige respeito para com o aluno, para com o processo de sua aprendizagem e para o próprio educador e sua profissão. Exige repensar a qualidade dos desafios oferecidos pelo professor ao aluno em uma perspectiva de superação dos próprios limites. Avaliar incide em decisões e escolhas individuais quanto as de grupo. Segundo Sem (2003, p. 5),

\footnotetext{
[...] no contexto individual, a imparcialidade pretende remover as influências tendenciosas representadas pelos objetivos, interesses ou preconceitos de um indivíduo, em oposição não apenas àqueles de outros membros de algum grupo do qual faça parte (podem ser muitos, como nacionalidade, classe, profissão, etc.), mas também aos de indivíduos estranhos a eles. A imparcialidade aberta é uma exigência para que os pontos de vista dos outros, quer eles pertençam ou não ao mesmo grupo específico, recebam uma atenção adequada.
}

\section{Paradigmas da avaliação}

Em um país como o Brasil, os sistemas de ensino mostram-se descentralizados política e institucionalmente, gerando reformas educacionais e sistemas de monitoramento e controle impulsionados pelas mais diversas razões (FERNANDES, 2004). Nas últimas décadas, a preocupação com a qualidade do ensino gerou propostas e sistemas de avalição como o Sistema de Avaliação da Educação Básica (Saeb), Provinha Brasil, Avaliação Nacional de Alfabetização (ANA), Exame nacional do Ensino Médio (Enem), Sistema Nacional de Avaliação do Ensino Superior (Sinaes). Os sistemas são instaurados como mecanismo para subsidiar os processos de formar e monitorar as políticas 
públicas, responsáveis por apontar caminhos ao aprimoramento das ações de melhoria da aprendizagem (CASTRO, 2009).

Aliado a isto, há dois paradigmas em todas as etapas do ensino. O primeiro, concebendo-o segundo a lógica de mercado e a avaliação como forma de controle; e outro, como um bem público, avaliado pela produção de sentidos. Tais paradigmas acabam possibilitando uma epistemologia e um modelo de avaliação com fundamentos científicos, ideologias e efeitos na vida social, política e econômica. Neste campo avaliativo, de acordo com Sobrinho (2004), podem-se encontrar múltiplas referências e também contradições.

A avaliação poderia possibilitar o afastamento da mera classificação, permitindo a análise da aprendizagem e a reorganização dos processos de ensinar e aprender, favorecendo a reflexão, a crítica e a expressão de ideias (ALBERTINO e SOUZA, 2004). Ainda podemos entender a avaliação como um ato desafiador ao professor e ao aluno ua reflexão de experiências vividas, na elaboração e reformulação de hipóteses. De acordo com Hoffmann (1993), é a possibilidade de direcionamento para um saber enriquecido, emergindo pela determinação em uma conduta de curiosidade, buscando, analisando, desconstruindo, reconstruindo, reinventando-se a cada dúvida. A prática de avaliação é um ato dinâmico, no qual o professor, em coparticipação com o aluno, por meio do diálogo e do respeito, compromete-se com a construção do conhecimento (SORDI, 1995). Este conhecimento seria construído a partir de saberes que fizessem sentido na vida cotidiana do aluno ou apenas para ultrapassar uma etapa exigida pelo sistema? Além disso, pergunta-se: Será que avaliamos nossos alunos durante 13 ou mais anos de estudo para prepará-los a concursos em um turno de um ou dois dias? Ou poderíamos tentar entender o que a vida poderia oferecer ou compartilhar com estes alunos em uma formação de respeito aos seus desejos ou interesses?

Meirieu (1994, p. 16) aponta que, como função classificatória, a avaliação constitui-se num instrumento estático. que

[...] não é tudo; não deve ser o todo, nem na escola nem fora dela; e se o frenesi avaliativo se apoderar dos espíritos, absorver e destruir as práticas, paralisar a imaginação, desencorajar o desejo, então a patologia espreita-nos e a falta de perspectivas, também.

Entretanto, avaliar alunos implica a imparcialidade acerca de problemas, potencialidades, desafios, mais dúvidas do que certezas (FERNANDES, 2004). Implica o estudo sobre o desenvolvimento cognitivo. Segundo este autor, implica analisar o que se passa atualmente com a avaliação das aprendizagens, em suas mais diversas dimensões, para que se possam identificar linhas de ação que venham a contribuir com a democratização, modernização e melhoramento do sistema educativo (FERNANDES, 2004). Oportunamente, abordamos a questão da imparcialidade e cabem as seguintes reflexões: somos 
imparciais quando praticamos nossa docência? Somos imparciais quando avaliamos os processos de ensinar e aprender? Somos imparciais quando nos auto avaliamos? Ou, ao contrário, seguimos a parcialidade de métodos, apostilas, de conhecimentos exigidos por uma ou outra instituição?

\title{
Instrumentalizando
}

\author{
"Só sei que nada sei" \\ (SÓCRATES apud EGG, 2009, p. 6)
}

Por muito tempo professores recorreram a provas que, segundo Luckesi (1991), não passavam de instrumentos de ameaça e tortura prévia dos alunos, podendo refletir mais tarde, inclusive, na vida profissional destes. Machado (1995) comenta que a rigidez demasiada e a pressão por parte do professor pode causar pânico no aluno, provocando o "branco" por nervosismo no momento da avaliação oral ou escrita, favorecendo, assim, a estigmatização, os traumas, com consequências por vezes irreversíveis.

A avaliação inclui o direito do aluno de participar em todo o processo, que, segundo Fleuri (1994, p. 98), "é o momento privilegiado de criticidade e criatividade coletiva", onde o aluno poderá sanar dúvidas e também questionar. Esta criticidade e criatividade coletiva naturalmente encaminham à compreensão e auto compreensão sobre o conhecimento - também chamado de metacognição.

Apesar de o termo metagognição ser relativamente recente na literatura, Sócrates já o referenciava, assim como Spinoza, ao proferir que "também, se alguém sabe alguma coisa, então ele sabe que ele sabe disso, e ao mesmo tempo sabe que sabe que sabe"1 (WEINERT,1987, p. 2). Ambos atentavam para o autoconhecimento. A metacognição ou metaconhecimento é a consciência sobre o próprio processo de aprendizagem ou o conhecimento do conhecimento (FIGUEIRA, 2003). Para John Hurley Flavell (1970) é conhecimento que o sujeito tem sobre o seu próprio conhecimento. E para Nisbett e Shucksmith (1986), é como se fosse o nosso "sétimo sentido". Somos seres únicos, singulares, exclusivos, como nossas impressões digitais e, portanto, com maneiras singulares de ver o mundo e aprender com e através dele. A partir do momento que desvendamos a maneira como aprendemos, podemos nortear todos os nossos saberes. Algumas pessoas aprendem mais facilmente quando escrevem, outras lendo, outras colocando em prática o conteúdo da aprendizagem, escutando, discutindo, a sós ou em grupo, ouvindo música, pesquisando na web, e poderíamos talvez escrever páginas sobre as diversas maneiras possíveis que mais se adaptam a uma pessoa mais que a outra. Porém, se há uma maneira singular de aprender em cada pessoa, cada aluno, podemos acenar para uma maneira singular de avaliar cada aluno, cada professor. E esta maneira não deve 
servir ao controle, seleção ou punição e tampouco seguir em apenas um sentido. Mas, como uma via de mão dupla em coparticipação professor e aluno, favorecendo a compreensão de ambos sobre os processos de ensinar e aprender, sobre o conhecimento e a maneira como se processa em cada um, para repensarmos o que seria uma avaliação significativa. Todavia deveria servir para que o professor pudesse se auto avaliar, se reavaliar, se reinventar constantemente, na busca de metodologias e instrumentos que venham a colaborar com cada aluno e com seu próprio aperfeiçoamento dentro de suas singularidades.

A exemplo de Foucault (2004), que tem um olhar voltado para a singularidade, para aquilo que dos acontecimentos foi excluído, não dito, não apresentado (BENETTI, 2010), o professor necessita do pleno exercício deste olhar atento, na busca por pistas que possam elucidar as maneiras singulares de nossos alunos na produção de conhecimento. Se ainda não conseguimos ouvir "o que não foi dito" ou tido como verdade, podemos atentar para o que nossos alunos dizem, escrevem, pensam, por meio de ferramentas como o Portfólio Reflexivo.

\section{Portfólio Reflexivo}

Para nortear a prática pedagógica em uma escola da rede pública de ensino no interior do estado do Rio Grande do Sul, as informações foram coletadas sobre o conhecimento produzido a partir de cada aula, junto aos anos finais do ensino fundamental por meio do Portfólio Reflexivo. O Portfólio utilizado consistiu em quatro perguntas, respondidas pelos alunos ao final de cada aula, em seus cadernos, sobre os temas abordados. As perguntas foram as mesmas para todas as aulas: $\mathrm{O}$ que eu sabia? $\mathrm{O}$ que eu aprendi? O que ainda preciso aprender? Como posso utilizar este conhecimento?

As respostas exigiam a subjetividade produzida por cada aluno dentro da heterogenia da sala de aula e, portanto, respeitada pelo professor. Em casa deveriam apresentar o Portfólio aos pais ou responsáveis, discutir com eles os argumentos e somente na aula seguinte apresentá-lo à análise do professor . O instrumento avaliativo foi empregado durante todo o ano letivo de 2017, aliado a outros instrumentos, como trabalhos em grupo, apresentações de trabalhos, atividades individuais e coletivas.

Mesmo que em um primeiro momento as questões do Portfólio pareçam simples, as respostas descortinaram revelações importantes para uma análise ampla dos sujeitos envolvidos nos processos de ensinar e aprender. Também funcionaram como um feedback aos pais ou responsáveis sobre os conteúdos trabalhados em sala de aula e o interesse dos filhos a respeito dos temas abordados. Quando este questionário retornou, o professor também teve seu feedback sobre o acompanhamento dos pais ou responsáveis, pelos alunos, sobre o nível de compreensão e interesse a respeito do assunto na 
visão de cada aluno. Isso permitiu reestruturar metodologias, estratégias e/ou conteúdos para um melhor desenvolvimento e aproveitamento do aluno. Também permitiu auxiliar o aluno na descoberta de como ele aprende, pois o instrumento avaliativo foi utilizado a partir de questões a serem respondidas pelo aluno. Assim, procuramos não utilizar as mesmas estratégias ou metodologias durante todo o período, alternando as aulas com o auxílio de vídeos, exploração do espaço escolar e seu entorno, jogos, questionários, grupos de discussão, trabalhos em grupos, produção de materiais diversos, apresentações de temas para outras turmas em formatos diversos ${ }^{1}$. A partir de cada atividade, percebemos reações diversas e efeitos diferentes em cada aluno. Enquanto alguns alunos apreciaram vídeos de documentários, não desviando olhares, lançando questionamentos coerentes sobre o conteúdo, outros alunos mostraram-se indiferentes. Outros ainda demonstraram desaprovação e desinteresse por meio de conversas paralelas que não diziam respeito à aula, brincadeiras, desenhos nos cadernos, e assim por diante. Houve alunos que preferiram um bom livro, outros uma discussão em grupo, outros escrevendo, escutando música, pesquisando na internet.

Com o portfólio foi possível conhecer um pouco mais sobre cada aluno, sua família, suas rotinas cognitivas, sociais, seus interesses e desinteresses, perspectivas, afinidades e inter-relações com colegas e professores. Assim, podemos inferir que um Portfólio Reflexivo contempla a produção da subjetividade dos alunos de forma contínua, adequando-se ao conhecer e ao conhecer-se, para que juntos - professor e aluno - consigam desvendar suas maneiras de compreensão e produção de conhecimento em cumplicidade. Ainda se apresenta como um instrumento avaliativo que permite conhecer com detalhes o aluno e também como fomento à sua própria compreensão e produção de subjetividade. Serve, ainda, como um convite à nossa autoavaliação como educadores, pesquisadores, mediadores e balizadores dos caminhos possíveis a percorrer para a compreensão do aluno a respeito do mundo que o rodeia e suas interações.

\section{Considerações como um convite a avaliar}

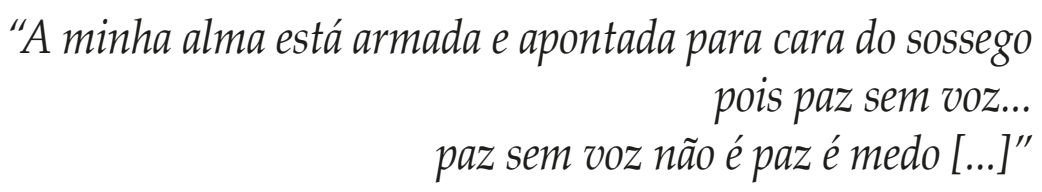

(O RAPPA, 2009)

A reflexão sobre o processo de avaliação sempre sugere alguns questionamentos, tais como: por que o aluno não aprende? Avaliamos para promover ou julgar o aluno? Enquanto professores, sabemos avaliar e nos auto avaliar? O que entendemos acerca dos 
processos de avaliação? Respostas a estas dúvidas ainda se apresentam como desafios a serem explorados, discutidos, compartilhados e, por vezes, geram mais questionamento e desconforto.

A avaliação deveria ser um momento de "fôlego", uma pausa para repensar a prática e retornar a ela, como um meio de julgar a prática. Utilizada como uma função diagnóstica, pode ser um momento dialético do processo para avançar no desenvolvimento da ação, do crescimento para a autonomia e competência.

Sabemos que mudanças não ocorrem por decreto e sim pela construção cultural, pelas revoluções e rupturas de paradigmas. E, para não transformar o processo avaliativo em patologia, nos cabe o convite a um novo olhar sobre a avaliação voltado ao conhecer e conhecer-se, implicando fundamentalmente a mudança de atitude, o desconforto, a discução, mas também o fazer. É deixar as conjugações no futuro do pretérito e recorrer ao presente. Fruto da imparcialidade de conceitos e pré-conceitos, de escolhas menos individuais e mais coletivas, com suas tomadas de decisões também em grupo.

Avaliação e auto avaliação por meio do Portfólio Reflexivo mostrou-se uma experiência enriquecedora, repleta de possibilidades para aluno e professor. Por meio dele, o professor balizou a seus alunos alguns caminhos possíveis para encontrar respostas às dúvidas, ditas ou não, mas disfarçadas nas entrelinhas. Também, a cada argumento oferecido pelo aluno foi possível reestruturar os conceitos de ensinar e aprender, em cumplicidade com ele, significando, ressignificando, reinventando-se a cada avaliação e auto avaliação. O trabalho com o Portfólio Reflexivo oportunizou um confronto de teorias, práticas e possibilidades no momento de planejar a prática pedagógica. Estimulou a pesquisa, a busca pelo conhecimento, bem como permitiu o exercício do olhar atento aos movimentos cotidianos da sala de aula em busca de sinergia.

Mas, até que ponto estamos dispostos a acrescer um trabalho a mais no rol de instrumentos e métodos avaliativos? Será que nós, professores, estamos "aptos" para nos auto avaliar dentro deste processo? Podemos inferir que este campo avaliativo abriga ainda um vasto percurso a ser desbravado, cheio de surpresas, armadilhas, encantos e dúvidas, que, necessariamente, serão enfrentados para que possamos evoluir nas práxis dos processos avaliativos de ensinar e aprender.

Recebido em: 15/10/2017, reapresentado em: 26/04/2018 e aprovado em: 27/05/2018

\section{Notas}

1 Texto original: "also, if somebody knows something, then he knows that he knows it, and at the same time he knows that he knows that he knows" (Spinoza: 1632-1677, in Weinert, 1987, p. 2). 
2 Enquanto um grupo apresenta o conteúdo em forma de teatro, outro grupo prefere criar a letra de uma canção, um happ. Outro grupo parte de uma maquete, e assim por diante.

\section{Referências}

ALBERTINO, Fátima Maria de Freitas; SOUZA, Nádia Aparecida de. Avaliação da aprendizagem: o portfólio como auxiliar na construção de um profissional reflexivo. Revista Estudos em Avaliação Educacional, São Paulo: Fundação Carlos Chagas, n. 29, 169-190, jan.-jun., 2004.

BENETTI, Cláudia Cisiane. Movimentos do ato de pensar: interlocuções possíveis entre Deleuze e Foucault. Revista Ensiqlopédia, Osório: CNEC, v. 7, n. 1, p. 49-64, outubro de 2010.

CASTRO, Maria Helena Guimarães de. Sistemas de avaliação na educação do Brasil: avanços e novos desafios. São Paulo em Perspectiva. São Paulo: SEADE, v. 23, n. 1, p. 5-18, jan.-jun., 2009.

EGG, Rosiane Follador Rocha. História da ética. Transcrição da Videoaula do Curso "Ética nas Organizações". Curitiba: IESDE, 2009.

FERNANDES, Domingos. Avaliação das aprendizagens: uma agenda, muitos desafios. Lisboa: Texto Editora, 2004.

FIGUEIRA, Ana Paula Couceiro. Metacognição e seus contornos. Revista Iberoamericana de Educación, Coimbra: OEI/CAEU, v. 33, n. 1 (número especial), p. 01-21, junho de 2003.

FLAVELL, John Hurley. Metacognitive aspects of problem solving. In.: L. B. Resnick (Ed.). The nature of intelligence. New York: Lawrence Erlbaum Associates, 1976.

FLEURI, Reinaldo Matias. Educar para quê? São Paulo: Cortez, 1994.

FOUCAULT, Michel. A hermenêutica do sujeito. São Paulo: Editora Martins Fontes, 2004.

HOFFMAN, Jussara Maria Lerch. Avaliação mediadora: uma prática em construção da pré-escola à universidade. Editora Mediação: Porto Alegre, 1993.

LUCKESI, Cipriano Carlos. Avaliação da aprendizagem escolar: apontamentos sobre a pedagogia do exame. Tecnologia educacional, Rio de Janeiro: ABT, v. 20, n. 101, p. 82-86, jul.-ago, 1991.

Avaliação da aprendizagem escolar. São Paulo: Cortez, 1995.

MACHADO, Maria Auxiliadora C. Araújo. Diagnóstico para superar o tabu da avaliação nas escolas. Revista AMAE Educando. Belo Horizonte: UNESC, n. 255, out.1995.

MEIRIEU, P. Prefácio. In: HADJI, Charles. A avaliação, regras do jogo: das intenções aos instrumentos. Portugal: Porto editora, 1994. Tradução de Júlia Lopes Ferreira e José Manuel Cláudio.

NISBET, J.; SHUCKSMITH, J. Learning strategies. London: Routledge \& Kegan Paul, 1986.

O RAPPA. Perfil. Faixa 1, A minha alma. São Paulo: Som Livre, 2009.

PECCI, J. C. O ramo de hortênsias. São Paulo: Círculo do Livro, 1986.

SEM, Amartya. Imparcialidade aberta e fechada. Revista ALCEU, Rio de janeiro: PUC, v.3 - n.6, p. 5-30, jan.-jul., 2003. 
SOBRINHO, José Dias. Avaliação ética e política em função da educação como direito público ou como mercadoria? Educação e Sociedade. Campinas: UNICAMP, v. 25, n. 88 (especial), p. 703-725, outubro de 2004.

SORDI, Maria Regina de. A prática de avaliação do ensino superior: uma experiência na enfermagem. São Paulo: Cortez/PUCCAMP, 1995.

WEINERT, F. E. Metacognition and motivation as determinants of effective learning and understanding. In.: WEINERT, F. E.; KLUWE, R. H. (Eds.). Metacognition, Motivation and Understanding. Hillsdale: LEA, 1987.

ZANELLATO, José Roberto. Portfólio como instrumento de avaliação no ensino de graduação em artes visuais. Dissertação (Mestrado em Educação)- Pontifícia Universidade Católica, Campinas, 2008. 